\title{
NOTAS SOBRE CAESAROBRIGA (TALAVERA DE LA REINA) Y SU PROBLEMÁTICA GEOPOLÍTICA EN LA ANTIGÜEDAD
}

\author{
Manuel Bendala Galán
}

\begin{abstract}
Resumen
El texto contiene una aproximación a la problemática urbana y urbanística de la ciudad originaria de Talavera de la Reina (Toledo), identificada con la romana Caesaróbriga, con atención a su relación con los precedentes urbanos de la zona, y a las razones básicas de la antigua y la nueva organización territorial.
\end{abstract}

\section{Summary}

This paper presents an archaeological approach to the urban and urbanistic problems posed by the fundational town at Talavera de la Reina (Toledo), which can be identified with Roman Caesarobriga. We pay special attention to the relationship of these remains with the urban background in the area, and also to the primary reasons for the old and the new principles of spatial organisation and articulation.

Nuestras investigaciones en la villa romana de Saucedo, junto a Talavera la Nueva, nos han invitado continuamente a mirar con interés la ciudad de Talavera de la Reina, que fue en la Antigüedad el centro económico y político de la comarca a la que la villa pertenece, del mismo modo que, hoy día, el pueblo vecino de ésta es un modesto municipio pedáneo dependiente de Talavera. Los muchos años en que han ido prolongándose nuestros trabajos en la villa -iniciados en 1982-, afectados por mil peripecias, han sido testigos de una simpática identificación con ella de los vecinos de Talavera la Nueva - "Talaverilla", como más afectiva y familiarmente la llaman-, y la tienen por origen remoto del mismo afán explotador de sus ricas tierras que dió lugar a su fundación en 1954, y siempre con la mirada puesta en el centro principal de Talavera de la Reina. De la potencia económica de esta notable urbe y de su importancia cultural dan sobrado testimonio la contundencia de 
su centro urbano, la riqueza de sus tradiciones, el temple, en suma, de una ciudad que siempre rivalizó con Toledo, capital de la provincia y últimamente de la Comunidad de Castilla-La Mancha, como tantas veces ocurre entre ciudades vecinas importantes, a las que la geografía, la historia y los designios inescrutables del destino o la suerte, otorgaron papeles distintos en su secular coexistencia.

La importancia en los tiempos pasados de Talavera de la Reina es bien conocida, con una trayectoria que ha dejado memoria en monumentos y tradiciones, algunas tan peculiares e interesantes como la famosa fiesta de Las Mondas, muy viva hoy en el calendario particular de los talaveranos. No ha sido, sin embargo, precisamente un ejemplo de saber crecer y desarrollarse económicamente en lo que atañe al respeto de su legado arquitectónico y urbanístico. El desarrollo vivido por la ciudad en los últimos decenios ha maltratado su apariencia urbanística, la que resultaba de su rica trayectoria histórica, de manera ya irreparable, a lo que algunos impulsos recientes tratan de poner algun remedio, decididos bastantes talaveranos a valorar y respetar cuanto sea posible la herencia monumental recibida, algo en lo que está en juego, se sepa o no, la identidad de Talavera y de sus gentes. Este nuevo espíritu, que se refleja en hechos como el impulso dado al Museo Ruiz de Luna, o en la mayor atención prestada al rico patrimonio arqueológico de la ciudad, visible o soterrado, nos anima también a mirar con más atención su trayectoria histórica, un interés que es precisamente el argumento que nutre estas pocas páginas.

No pretendo ir más allá de un somero acercamiento a una cuestión ampliamente tratada en los últimos años, pero mal conocida todavía, decantada en un status quaestionis que sólo una investigación más profunda y sosegada podrá superar, y a la que quisiera contribuir con algunas observaciones. Empezando por lo más elemental o más generalmente admitido, cabe recordar que Talavera de la Reina resulta ser un centro urbano que perpetúa la antigua Caesarobriga, como parecen probar epígrafes latinos documentados a partir del siglo XVI. De la ciudad romana se sabe todavía poco -por las transformaciones urbanísticas medievales y posteriores y por la escasa atención prestada a los restos arqueológicos-, y de su raigambre prerromana, sugerida por el sufijo céltico en -briga, todavía menos.

El nombre antiguo de la ciudad, Caesarobriga, hace patente una fundación romana, que no ha de tenerse por contradictoria con que sus raices sean anteriores, raices que se insertan en un plano que no es el estrictamente urbanístico, sino el urbano u organizativo del territorio en que se halla. Como han subrayado investigadores de toda solvencia, el nombre de la ciudad, como los de Iuliobriga y Augustobriga, indican una fundación augustea, aunque integrara a individuos que no tenían ciudadanía romana, de modo que era una ciudad peregrina, como indica expresamente Plinio al incluirla entre las localidades estipendiarias de la Lusitania $(N . H .4,118)^{[1]}$.

Puede barruntarse, por tanto, una reorganización de las gentes y de los asentamientos de la zona por aplicación de la conocida fórmula del sinecismo o la contributio, enten-

[1] La problemática general puede verse en los trabajos recientes de Alföldy, 1987, 58-59 y passim, y de Mangas y Carrobles, 1992 y 1998. 
dible como renovación promovida en función de los criterios de organización romanos, y también como acción inserta un proceso de estructuración que tiene precedentes en la dinámica general de la zona ${ }^{[2]}$. La consolidación de la ciudad -sea fundación estricta o refundación- en la organización romana tendría lugar en época flavia, a lo que apuntan algunos indicios -la paleografía de las inscripciones de magistrados, o la significativa pertenencia de algunos personajes de la ciudad a la tribu Quirina (Alföldy, 1987, 59)-, de modo que entonces, en el marco de la municipalización general de Hispania, adquirió Caesaróbriga estatuto municipal ${ }^{[3]}$.

No he mencionado, ni voy a tratar por extenso, la compleja problemática acerca de la indicada identificación de Caesarobriga con la ciudad antigua de Talavera de la Reina. Es una cuestión muy debatida, como recientemente han comentado J. Mangas y J. Carrobles, quienes, al cabo de su propia reflexión, concluyen que lo más firme que hoy puede decirse es que parece acertada esa identificación, admitida, por lo demás, por Hübner, Galsterer, Tovar, Alföldy y muchos otros (Mangas y Carrobles, 1992, 97-99). Es una identificación que plantea, sin duda, problemas a la vista de las indicaciones de los itinerarios, sobre todo en la fuente principal del Itinerario de Antonino, ya que es bien de extrañar que no sea citada en la vía de Augusta Emerita a Caesaraugusta, donde se relacionan, a partir de la capital lusitana, las mansiones de Lacipea, Leuciana, Augustobriga, Toletum, Titulcia, Complutum..., y así hasta Zaragoza (I.A. 438,2-439,4; Roldán Hervás, 1975, 86-87; Álvarez, 1992). La importancia del lugar de Talavera, en el pasillo del Tajo, y otros datos han llevado a algunos a sostener que aquí estuvo la Augustobriga citada en el Itinerario. Pero la cuestión -que me parece de lo más interesante- debe quedar por ahora en suspenso, y tal vez nuevas inscripciones u otros indicios permitan resolver definitivamente la cuestión.

Aceptada, por ahora, la identificación más ampliamente admitida con Caesarobriga, me interesa más destacar aquí la dinámica cultural relativa al proceso de maduración organizativa que culmina o explica la aparición de la ciudad. Se halla ésta, en efecto, en una zona fronteriza entre los vettones y los carpetanos (González-Conde, 1986), un punto de no poco dinamismo cultural desde que cuajan en la Península las culturas complejas del Bronce Final o el Hierro I[4]. Junto a la capacidad de irradiación del mundo atlántico o de las culturas meseteñas, fue un factor decisivo la consolidación en el mediodía peninsular de la cultura tartésica, cuya importancia como foco principal de organización inicial de las entidades estatales y urbanas en la Península está ampliamente contrastada, así como su papel catalizador de una dinámica que llegaría a afectar a la casi totalidad del territorio

[2] Para una visión general de la evolución urbana de los vettones, en relación con la de los lusitanos y otros pueblos vecinos, y la acción romana, puede verse el trabajo de Salinas de Frías, 1990. Un detenido estudio históricoarqueológico de la evolución urbana de su ámbito lo proporciona Fuentes Domínguez, 1993.

[3] También, para el conjunto de la estructuración urbana de Hispania, puede verse con provecho el libro de Abascal y espinosa, 1989.

[4] Una visión general, en Blasco, 1993, 145 ss.

[5] Un estudio personal de la cuestión, en Bendala, 1989. 
peninsular ${ }^{\{5 \mid}$. Bien conocida es su irradiación hacia el interior de la Península o la incoporación más o menos acentuada a su órbita de amplias regiones de la Meseta desde tiempos bastante antiguos, una cuestión de la que van surgiendo contínuas pruebas arqueológicas.

En relación con la zona concreta que ahora nos ocupa, cabe recordar inicialmente la significativa aparición de estelas de guerreros o "del suroeste" en la región de Talavera: una en las inmediaciones de la ciudad misma -los cerros conocidos como "La barranca del águila" (Portela y Jiménez Rodrigo, 1996)-, dos en el término de Las Herencias (FernándezMiranda, 1986; Fernández-Miranda y Pereira, 1992; Moreno Arrastio, 1995), y una cuarta, algo más distante -55 kilómetros al suroeste de Talavera-, en Aldeanueva de San Bartolomé (Pacheco et alii, 1999). Las cuatro se alinean en el camino que marca aproximadamante el discurrir del Tajo ${ }^{[6]}$, desde Talavera hasta Puente del Arzobispo siguiendo el curso del río, después girando hacia el sur, hacia la mencionada localidad de Aldeanueva, en un recorrido que discurre por la vaguada que queda entre las Sierras de Altamira (que sirve en parte de limite entre las actuales provincias de Toledo y Cáceres) y de Sevilleja. El camino indicado coincide parcialmente con un tramo de la Cañada Leonesa Oriental, una ruta principal, por tanto, en el trasiego de ganados de la Mesta (Klein, 1979; García Martín, 1990), que debió de aprovechar, como tantas otras, caminos naturales o marcados por un uso de larga tradición.

Los contactos que las estelas representan se ratifican en su continuidad con hallazgos de productos correspondientes a la oleada orientalizante ${ }^{[7]}$, documentados en las Fraguas, Casa del Carpio y otros lugares próximos, así como en otros de la misma área (Fernández-Miranda y Pereira, 1992), como el no muy lejano asentamiento de El Raso de Candeleda (Fernández Gómez, 1986, 479-80). En ellos se tiene la prueba material de contactos que debieron de contribuir a crear, según avanzaba el primer milenio, estructuras organizativas más complejas y formas de hábitat más evolucionadas. Contaba en todo ello la riqueza pecuaria de la zona, y también una riqueza minera en la región de los Montes de Toledo que en fechas maduras de la Protohistoria hubieron de ser un factor principal de acumulación de riquezas, de jerarquización social y, en una palabra, de complejización cultural. Pienso a estos efectos en la vecindad de centros tan notorios como Sisapo, en La Bienvenida (Ciudad Real), cuya secuencia cultural revela una pronta vinculación al mundo tartésico (Fernández Ochoa et alii, 1994; Esteban Borrajo, J., 1998), orígen de una riqueza y una fama en la Antigüedad que tendrían su más clara manifestación en época romana. Y por otro lado, en relación con nuestro foco de interés, cabe pensar en la misma dirección

[6] Las estelas figuran entre los elementos más significativos de un temprano contacto, a partir del Bronce Final, entre el ámbito tartésico y la Meseta. Su aparición en puntos que siguen el curso del Tajo, señala una ruta de penetración que desde el suroeste podrían remontar el río siguiéndolo aguas arriba y explicar, entre otras cosas, el hallazgo en el valle del Ebro, en el término zaragozano de Luna, la conocida estela con instrumento musical de cuerda y escudo de la misma familia. No es que las estelas puedan, a mi entender, explicarse como hitos específicos de caminos, según se ha propuesto (Ruiz Gálvez y Galán, 1991; Galán, 1993), pero sí aparecen asociadas a los ámbitos y las rutas que quienes las hicieron pretendían controlar para explotar los recursos que les importaban, sobre todo mineros o metálicos, y controlar su comercio.

[7] Algunos datos y planteamientos explicativos recientes, por ejemplo, en: Galán, 1993; Cerdeño et alii, 1996 ; Martín Bravo, 1998; Barrio Martín, 2001 (e.p.). 
en la importancia del eje de comunicación e intercambios que representó la que cuajaría como "Vía de la Plata". Talavera se halla en un punto en el que confluyen, entre otras, influencias procedentes de estos dos vectores de desarrollo económico y cultural.

La dinámica catalizada en torno a ejes como los indicados, tendría como consecuencia una estructuración del territorio que, aparte de numerosos asentamientos a la manera de pequeños castros, en su mayoría poco o nada estudiados, se anclaba en centros importantes de notable entidad, como el de Arroyo Manzanas, en Las Herencias, a apenas siete kilómetros de Talavera (Moreno Arrastio, 1990), o el algo más lejano de El Raso de Candeleda. Éste último, para el que se cuenta con un buen estudio (Fernández Gómez, 1986) y con la posibilidad, gracias a ello, de disponer de bases firmes a la hora de valorar su historia, su configuración y su papel en la zona, es un magnífico ejemplo de castro creado en época tardía, seguramente por aglutinación o sinecismo de otros menores, para un mejor control económico y político de una zona de notable interés estratégico en el piedemonte de la Sierra de Gredos. El estudio del castro, de la necrópolis vecina, algo anterior, y la valoración del entorno, han llevado a su excavador a deducir que fue fruto de una concentración del hábitat de la zona en fechas situables a fines del siglo III a.C. (Fernández Gómez, 1986, 520), con la constitución de un castro que alcanzaba la considerable extensión de unas veinte hectáreas, reciamente defendido con muralla y fosos, y dotado de una urbanística muy avanzada, con calles y manzanas de casas bien ordenadas, que sobresalen por su firme tipificación y la considerable superficie de muchas de las excavadas. Obedecen a dos tipos, uno alargado considerado de tradición centroeuropea, y otro, más complejo, de planta centrada en torno a una amplia estancia destinada fundamentalmente a cocina y sitio de estar, que se tiene por correspondiente a influjos mediterráneos (Fernández Gómez, 1986, 486), aunque se advierta una disposición que, con nueva complejidad, mayor anchura y más habitaciones, mantiene en su eje longitudinal la ordenación del tipo más sencillo. Al segundo tipo, en cualquier caso, corresponden casas muy funcionales y obedientes a un patrón doméstico muy articulado y bien fijado, que con particular fuerza se convierte en reflejo de una sociedad madura, firmemente apegada a prototipos arquitectónicos que traducen fielmente la solidez de sus estructuras familiares y suprafamiliares, y su articulación en una comunidad que, si bien no ofrece rasgos de una gran jerarquización, sí responde o se acerca mucho a patrones de sociedades desarrolladas, incorporadas a la vida plenamente urbana, tal y como las conocemos en el mundo ibérico ${ }^{[8]}$.

Ejemplifica, por tanto, el asentamiento de El Raso una evolución hacia las formas complejas de la vida urbana que puede definirse como resultante de un proceso de "iberización"|91, fruto de contactos cada vez más intensos con las culturas más desarrolladas de la periferia ibérica, como, en las proximidades de Toledo, demuestran yacimientos como el interesante santuario de Illescas (Valiente, 1994), o tantos otros (Fuentes, 1993). En el mundo propiamente celtibérico se constata el mismo fenómeno (Burillo, 1998), con datos

[8] Una cuestión ampliamente tratada en la investigación de los últimos años, como expongo en mi trabajo: Bendala, 1998 (y tratan también los demás incluidos en las Actas del Congreso en que se dió a conocer: Aranegui, ed., 1998).

[9] Una amplia reflexión, en: Almagro-Gorbea, 1994, 26 y passim. 
arqueológicos o con expresivas noticias transmitidas por las fuentes literarias. El historiador alejandrino Appiano, en su Historia romana, uno de los escritos más interesantes al caso, comenta los conocidos hechos relativos a los lusones, que, en el año 181 a.C., se refugiaron en Complega, una ciudad -polis, la llama- que había sido fundada muy poco antes, se había fortificado y había crecido muy rápidamente (Iber., 42). Y el mismo fenómeno afectó, en un hecho más famoso y cargado de consecuencias, a la ciudad de Segeda, situada en Poyo de Mara (Zaragoza). Ésta, escribe Appiano, "ciudad de los celtíberos llamados belos, grande y poderosa, estaba inscrita en los tratados de Sempronio Graco. Esta ciudad forzó a otras más pequeñas a establecerse junto a ella; se rodeó de unos muros de aproximadamente cuarenta estadios de circunferencia y obligó también a unirse a los titos, otro pueblo limítrofe" (Iber., 44).

La ciudad de Segeda debió de fundarse a fines del siglo III a.C., una época que en amplias zonas de la Celtiberia y de la Meseta debió de ser testigo de un proceso de estructuración del hábitat según modelos ya urbanos o muy próximos a ellos, en lo que hubo de jugar un papel importante la penetración, como decía, de las influencias genéricamente calificables de "ibéricas" (Almagro-Gorbea, 1994), aunque en determinadas zonas debió de jugar un papel importante la influencia específicamente púnica, sea en la etapa correspondiente a la acción de los Barca, sea también un fenómeno remontable a los años inmediatamente anteriores ${ }^{[10]}$, que enlazarían, en último término, con la poderosa influencia ejercida en las zonas que ahora nos interesan, como veíamos, desde la fase orientalizante, según acabo de comentar. Precisamente en los ámbitos lusitano y vettón se comprueba una influencia muy poderosa de los púnicos, resultado de un proceso todavía impreciso, pero que hubo de ser de considerable peso en el grado de alta articulación social, económica y urbana que va demostrando la Arqueología y se advierte con una lectura más atenta de las fuentes literarias cuando describen las actividades de Viriato, más un "principe" a la cabeza de ciudades coaligadas frente a Roma que un "bandolero" de éxito en imperiosas y casi románticas actividades de pillaje ${ }^{[111}$. Tómese como un dato tal vez revelador el nombre de Púnico que, según las fuentes (Appiano, Iber.,56), tenía uno de los más poderosos príncipes lusitanos que se enfrentaron a los ejércitos de Roma.

En suma, a la hora de su incorporación a Roma, el ámbito de Talavera se hallaba envuelto en una dinámica de organización y control territorial que, como venimos comprobando y tratando de demostrar en los últimos años ${ }^{[121}$, se anticipa o prepara la acción romana, con la potenciación mediante sinecismo de núcleos importantes en los que asentar la articulación del territorio según las exigencias económicas y políticas de una época marcada por la creciente universalización, por la integración en las vastas redes de relaciones que, siguiendo patrones helenísticos, cementará el descomunal Imperio Romano. Roma

[10] He tratado de la cuestión en: Bendala, 1987 y 1994, entre otros estudios. Una interesante consideración de lo mismo con base en los expresivos testimonios numismáticos, en: García-Bellido, 1991-92 y 1993. Sobre el significado de las campañas de Aníbal en tierras vacceas, véase: Domínguez Monedero, 1986.

[11] Un enriquecedor análisis de este extremo histórico e historiográfico, se debe a García Moreno, 1989, 31 ss. Algunas ideas en la misma dirección, también sugeridas por Chic, 1980.

[12] Véase a este propósito el trabajo colectivo: Bendala, Fernández Ochoa, Fuentes y Abad, 1988. 
va a consolidar, y ultimar a nuestros efectos, el mismo proceso de concentración con la creación de nuevos centros, como los de Augustobriga o Caesarobriga. Añadirá a la trayectoria anterior, también sin duda, nuevos elementos, que serán decisivos en la definitiva configuración de la trama urbana de Hispania; entre ellos los derivados del interés máximo puesto en facilitar la vialidad -con fines políticos y económicos- de las tierras incorporadas al Imperio, para lo que se aplicarán fórmulas muy "modernas" de control territorial, apoyadas ahora en una redoblada capacidad de conocimiento geográfico y de su proyección cartográfica ${ }^{[13]}$. Y algo de esto puede percibirse en la fundación la ciudad antigua de Talavera de la Reina (sea Caesarobriga o algunos de los otros nombres antiguos que se barajan para su identificación).

El lugar de Talavera significa la elección de un punto nodal de gran importancia estratégica en la comunicación entre el centro de la Meseta -la Carpetania- y el occidente peninsular -la Lusitania o, más próxima y exactamente, la Vettonia- a través del paso del Tajo. La fijación del control territorial mediante vías de tránsito asegurado por calzadas más firmes y estructuradas pudo conducir a la elección del lugar de Caesarobriga/Talavera en un punto principal para el cruce del Tajo, cerca del paso sobre el Alberche a través de un puente, y núcleo urbano destinado a controlar directamente el que salvaba el Tajo, al que queda asociado como otra de tantas "ciudades pontuarias". En la reorganización de Hispania acometida a fines de la República y, sobre todo, por Augusto, fruto de la ultimación de la conquista y de la maduración imperial y organizativa de Roma, algunas de las ciudades clave de la trama viaria destinada a articular las tierras del interior, que lo necesitaban más, van a ser precisamente ciudades destinadas a controlar el cruce de cursos fluviales de importancia mediante puentes, con casos tan señalados como Augusta Emerita y Caesaraugusta, que fijaron puntos de paso principales sobre el Guadiana y el Ebro respectivamente. Ambas, además, significan retoques de gran relevancia -e innegable virtualidad por la importancia adquirida hasta nuestros días por estas ciudades en la articulación de sus respectivos territorios y su integración en el conjunto de Hispania- respecto de las organizaciones precedentes, fueran vernáculas o ya romanas de momentos anteriores, todo lo cual puede ser atribuido al nuevo nivel de capacidad proyectiva que descansaba en el mencionado progreso geográfico y cartográfico.

Como punto nodal de control de su propio territorio, el nuevo centro urbano fue poblado mediante la concentración o sinecismo de los habitantes de otros asentamientos de la zona, que perdían con ello su papel y quedaron abandonados. A este fenómeno hay que atribuir, como se ha hecho ya (Fernández Gómez, 1986, 949; Álvarez Sanchís, 128), el abandono de El Raso de Candeleda y del más cercano asentamiento de Arroyo Manzanas.

Las excavaciones en El Raso han hecho ver que su amortización no fue traumática, propiciada por guerras, incendios u otras causas violentas, sino consecuencia de un abandono por traslado en el curso del cual pudieron llevarse sus enseres y ganados. Las monedas halladas en el asentamiento aseguran que tal cosa hubo de ocurrir con posterioridad al 47 a.C., fecha de acuñación de las más recientes recuperadas en el mismo. Precisamente

[13] Según argumenté ampliamente en: Bendala, 1990, en particular, 38-40. 
las ocultaciones de monedas y otros objetos de valor, y el que no haya acontecimientos bélicos relevantes posteriores a César, han conducido a pensar en un abandono en la misma época cesariana o muy poco posterior (Fernández Gómez, 1986, 520-526). Pero el hecho de que fuera un traslado pacífico, que los habitantes del castro pudieron preparar llevándose cuanto les podía ser útil, permite pensar también en una marcha algo posterior, no acuciada por decisiones apresuradas tomadas en o como consecuencia de un conflicto bélico, sino fruto de una planificación sosegada, adoptada en el marco de un programa de organización territorial en el marco de la "pax romana". En cualquier caso, cuanto ahora sabemos invita a mantener la idea de una conexión entre el abandono de El Raso y, seguramente también, de Arroyo Manzanas, y la fundación de Caesarobriga/Talavera como consecuencia de un programa de estructuración augusteo y englobable en un proceso de alcance que se funde $-\mathrm{y}$ hasta se confunde- en bastantes cosas con la obra de César, un nombre que se hace en nuestro caso particularmente presente por la denominación misma de la ciudad.

Los habitantes de la nueva urbe mantuvieron su condición de peregrinos ${ }^{[14]}$, con obligaciones estipendiarias, agrupados ahora en una ciudad de estatuto no privilegiado ${ }^{[151}$. El arraigo en las comunidades "indígenas" de la zona se pone de manifiesto en el nombre oficial de la ciudad promovida por Roma, que mantiene el característico sufijo céltico en -briga $a^{[16}$, y en realidades tan significativas como la veneración de divinidades indígenas -entre las que destaca la ilustre Ataecina-, la constatación de antropónimos no romanos -Aunia, Dangetus...-, o la perduración de organizaciones suprafamiliares documentadas en los epígrafes -Alionicum, Pistiricum...- (Mangas y Carrobles, 1992, 105-106).

Quizá sea una contundente expresión de la dependencia de las organizaciones anteriores el hecho de que la ciudad no haya perpetuado el nombre de Caesaróbriga con las evoluciones fonéticas que fuera (como Mérida, de Emerita; o Zaragoza, de Caesaraugusta), sino la denominación de Talavera -Talabira en la documentación musulmana (Martínez Lillo, 1998, 19 ss.)-, que corresponde a un topónimo también de raigambre céltica, del tipo de Talabara o de Talabriga, asociable además al nombre de una Ebora que estaba por la misma zona. La cita Livio $(40,30)$ a propósito de las actividades de Q. Fulvio Flaco, quien, en el 181 a.C., hubo de hacer frente a una coalición de pueblos de la región que nos ocupa, y en el curso de la campaña situó su campamento junto a la ciudad mencionada, además de establecer en ella una pequeña guarnición: castra locavit ad oppidum Aeburam, modico praesidio in urbe posito. F. Fernández Gómez ha planteado la posibilidad de que esa Ebora -de nombre igualmente indoeuropeo-, con la que los romanos tuvieron buena rela-

[14] Seguramente durante mucho tiempo (Mangas y Carrobles, 1992, 108), mientras la élite, a partir de la municipalización flavia, y por los caminos que conocemos, fue incorporándose a la situación privilegiada de ciudadanos romanos.

[15] La problemática urbana de Caesarobriga y de su ámbito, en sus raices y planteamientos romanos, ha sido ampliamente tratada por Alföldy, 1987, 100-101 y passim.

[16] Es una adscripción etnocultural de este tipo de topónimos bien conocida, para cuya contextualización en la Península y su expansión en el ámbito indoeuropeo, puede verse el trabajo de Albertos Firmat, 1990 y una consideración más reciente de la forma toponímica y las lingüisticamente próximas, en: Villar, 1995, 153-188. 
ción, fuera identificable con el castro de El Raso; el nombre quedaría recordado en el propio de Talavera, que añade el radical $\mathrm{Tal}^{-171}$, y en otros topónimos de la zona, como Talaveruela o la misma comarca de la Vera, que queda en las proximidades (Fernández Gómez, 1986, 939-941), a lo que añade la sospecha de que la relación onomástica entre Ebora y Talavera fuera expresión del hecho de que los habitantes de la primera se hubieran trasladado a la nueva urbe promovida por Roma, como otros también opinan.

El nombre de Talavera, que se aparta del "oficial" de Caesarobriga, remite, seguramente por tanto, al nombre de la comunidad más importante integrada en la nueva ciudad, y el arraigo de la denominación vernácula haría que se impusiera sobre la romana, del mismo modo que Corduba sobrevivió al de Colonia Patricia, Híspalis al de Colonia Rómula, y tantos otros. Este fenómeno, por otra parte, puede significar mucho más que el afán patriótico de mantener la propia identidad etnocultural, y responder al hecho de que la nueva realidad organizativa aprovechaba mucho de la previamente existente, incorporada tan directamente como probaría la perpetuación de la denominación. Roma, pues, habría procedido a un cambio urbanístico, partiendo de una organización urbana o protourbana importante para su zona, aunque proyectándola ahora a un horizonte más amplio, el propio de la vastísima organización territorial del Imperio cimentada en su extraordinaria red viaria, al que incorporaba definitivamente una Hispania políticamente unificada.

Caesarobriga quedó englobada en la provincia Lusitania, con una vinculación geocultural que perpetuaba su pertenencia al ámbito vettón, detectable, entre otras cosas, en la repartición de los famosos verracos y en otros detalles perseguidos en estudios arqueológicos ya bastante pormenorizados. La organización romana, pues, vuelve en ésto a demostrar una lógica adecuación a las estructuras organizativas y etnoculturales preexistentes, reafirmadas con nuevos horizontes, como decía, y nuevas vinculaciones en la globalización política romana, en lo cual Caesarobriga tendrá un considerable papel como ciudad limítrofe, extremo oriental de una provincia que fijará nexos bastante firmes con Mérida como capital y su entorno, y con consecuencias en la caracterización cultural del ámbito caesarobrigense, que pueden detectarse en datos arqueológicos correspondientes a época romana, o rastrearse en el perfil cultural de la zona hasta tiempos más recientes ${ }^{[18]}$.

En el nuevo régimen económico y político va a seguir contando la importancia ganadera de la zona y se subrayará la dedicación a la minería, con importantes precedentes también y convertida ahora en uno de los factores principales de enriquecimiento y consolidación de las élites locales romanas o romanizadas (Mangas y Carrobles, 1992). Pero en el marco de las actividades derivadas de la definitiva incorporación al Imperio va a ser esencial la actividad agraria, la explotación intensiva del campo, en lo que también habría de

[17] A. Tovar, en sus notas a la ciudad de Talabrica (Tovar, 1976, 257), recoge la opinión que lo iguala al céltico talos, 'frente', que en lengua bretona significaria 'cerca de'.

[18] La importancia de la línea de vertebración territorial, para el conjunto de la Península, señalada de forma aproximadamente diagonal por el curso del Tajo, en su percepción antigua y la que en el mismo sentido se tuvo en época visigoda, ha sido bien señalada por García Moreno, 1990; entonces, en un eje del que se tenía una plena conciencia geográfica, adquirió un papel prioritario Toledo, con evidentes consecuencias en la historia posterior de nuestra zona. 
jugar un papel importancia la nueva estructuración apoyada en centros como Caesarobriga. Sería interesante conocer bien el territorio específico de la ciudad, que es de suponerlo comprendido entre fronteras situadas, aproximadamente, en una línea intermedia sobre la distancia a Talavera la Vieja (¿Augustobriga?) por el oeste, la Sierra de Gredos al norte, las estribaciones septentrionales de los Montes de Toledo al sur y una frontera oriental -límite de la Lusitania y la Tarraconense y frontera con el territorio de Toletum-, que suele situarse hacia la línea Escalona-Navahermosa ${ }^{[19 !}$.

Una prospección detenida de la zona y el estudio de las villae del entorno de Talavera y sus respectivos territorios daría bastante de sí y es cuestión en la que se trabaja en la actualidad con diversas iniciativas. La villa mejor conocida de la zona, la de El Saucedo ${ }^{[201}$, nos proporciona el dato relevante de una ocupación desde el siglo I d.C. que responde, seguramente, a una estructuración del campo según el típico modelo de explotación basado en la multiplicación de villae en torno a un núcleo urbano principal, que debió de desarrollarse con fuerza definitivamente desde la municipalización flavia, modelo que iría sustituyendo -con una conviviencia más o menos parcial y prolongada- al de los castros u otros sistemas anteriores.

Quizá el propósito de dedicar una zona de arraigada tradición ganadera a una vida agraria más intensa explique uno de los rasgos culturales más atractivos e interesantes de la tradición talaverana: la fiesta de las Mondas, con centro en la ermita de la Virgen del Prado, situada extramuros de Talavera. Si, como bien parece, son la pervivencia cristianizada de la fiesta primaveral del mundus cereris (Caro Baroja, 1974, 31-73), con la ofrenda a Ceres -diosa de la agricultura, que se incorpora como teónimo a la designación del cereal, fruto por antonomasia de la explotación del campo- de las primicias de cada cosecha, tendríamos con ellas "fosilizada" una práctica que pudo estar al servicio del afán por consolidar la actividad agrícola, o ser, simplemente, un reflejo de su pujanza en los tiempos romanos. Las ofrendas aportadas por los diferentes pueblos o aldeas del entorno serían, además, el recuerdo del papel central de Caesaróbriga, de la dependencia de la ciudad de los centros menores dedicados a la directa explotación agrícola de su fértil comarca.

Sin más ambición que un sondeo, verdadera escaramuza intelectual, que trate de aprovechar para nuestros propósitos la tradición hibernada en las Mondas, podríamos tener en consideración los lugares tradicionalmente participantes como oferentes de la Virgen del Prado por si sugieren algo en relación con el antiguo territorium caesarobrigensis. En una Historia de Talavera del siglo XVI debida a Cosme Gómez Tejada, se cita como aportadores de mondas o cirios -las dos modalidades de ofrendas contempladas en la ritualidad de las fiestas- los siguientes lugares: Mejorada y Cegilla, dependientes del Conde de Oropesa;

[19] Alföldy, 1987, 59. El mismo autor subraya (ibid.) el hecho de que hubo de disponer Caesaróbriga en su territorio de centros menores dependientes de él, necesarios para su articulación y explotación, en relación con uno de los cuales -tal vez situado en Vascos, junto a Navalmoralejo, ya en la margen izquierda del Tajo, bastante al sur del río- habría de estar una inscripción (CIL II, 5.320) que da cuenta de un individuo que hace constar su condición de Cae(sarobrigensis), y que procedía ex (k)ast(ello) Ciselli.

[20] Remito a una de las publicaciones más recientes y sintéticas acerca de la villa (Bendala, Castelo y Arribas, 1998), que contiene el resto de la bibliografia. 
Gamonal, Peña del Cuervo, Yllán de Vacas, Pepino, Brujel, Calera, Santa Cruz, Billanueva, Ciencias, Cazalejas, Chozas, Montearagón y El Casari211. Dibujan en conjunto un territorio que enlaza las tierras del oeste de la ciudad de Talavera con una más amplia penetración al este, hasta donde, más o menos, suele situarse el límite oriental del territorio caesarobrigense. Cerca queda, como anunciando el comienzo del antiguo territorio toletano, la localidad de Portillo de Toledo, y más a sur y al este, la de Villamiel de Toledo, ambas algo al este de la línea que trazan, de norte a sur, los pueblos de Escalona, Maqueda y La Puebla de Montalbán ${ }^{[22]}$.

Tendríamos, pues, un territorio determinado por una intensificación de la actividad agrícola, que facilitaba la feracidad de los valles del Tajo y el Alberche, con unas pocas cabeceras en centros que, en conjunto, ofrecen para esta zona una urbanización poco densa, que también se traduce en una todavía limitada concentración de villae, como ponen de relieve los estudios arqueológicos (Gorges, 1990). El futuro dirá la última palabra sobre toda la problemática considerada, con los resultados de más prospecciones y excavaciones, de cuya intensificación en los últimos años, y del interés creciente de los talaveranos por la recuperación de su historia y su patrimonio, cabe esperar buenos resultados.

[21] Datos recogidos por Caro Baroja, 1974, 37-39.

[22] El territorio en época medieval, bien estudiado por Suárez Álvarez (1982, 73 ss.), puede servir algo a nuestros propósitos, aunque la última palabra la dirán prospecciones y estudios arqueológicos más sistemáticos que están por hacer. Era entonces un territorio bastante extenso, que bajaba muy al sur -una prolongación al otro lado del Tajo que sí parece remontarse a los tiempos antiguos, según se comentó poco más arriba-, hasta llegar al Guadiana, todo lo cual fue resultado de las fricciones y empujes entre el municipio y los ámbitos señoriales del entorno. 


\section{BIBLIOGRAFÍA}

AA.VV., 1992: Acta de las Primeras Jornadas de Arqueología de Talavera de la Reina y sus tierras, Toledo.

ABASCAL, J.M. y ESPINOSA, U., 1989: La ciudad hispano-romana. Privilegio y pioder, Logroño.

ALARCÂO, J. et alii, 1990: "Proposition pour un nouveau tracé des limites anciennes de la Lusitanie romaine", en J.-G. Gorges (ed.), 1990, 319-329.

ALBERTOS FIRMAT, M².L., 1990: "Los topónimos en -briga en Hispania”, Veleia, 7, 131-146.

ALFÖLDY, G., 1987: Römisches Städtewesen auf der neukastilischen Hochebene. Ein Testfall für die Romanisierung, Heidelberg.

ALFÖLDY, G., 1999: “Aspectos de la vida urbana en las ciudades de la Meseta Sur”, en González (ed.), 1999, 467-485.

ALMAGRO-GORBEA, M., 1994: “Urbanismo de la Hispania 'céltica'. Castros y oppida del centro y occidente de la Península Ibérica", en Almagro-Gorbea y Martín (ed.), 1994, 13-75.

ALMAGRO-GORBEA, M. y MARTÍN, A.M². (Ed.), 1994: Castros y oppida en Extremadura, Complutum extra 4, Madrid.

ALVAR, J. y BLÁNQUEZ, C. (ed.), 1990: Toledo y Carpetania en la Edad Antigua, (Toledo, 1986), Toledo.

ÁLVAREZ, Y., 1992: "Aportación documental para el estudio del trazado de la vía romana entre Talavera de la Reina y Toledo", AA.VV., 1992, 159-176.

ÁLVAREZ-SANCHÍS, J.R., 1999: Los vettones, Madrid.

ARANEGUI, C. (ed.), 1998: Actas del Congreso Internacional "Los Iberos, Príncipes de Occidente", Barcelona (1987).

BARRIO MARTÍN, J., 2001: "El santuario doméstico del poblado prerromano de Cuéllar (Segovia). Un análisis del contexto arqueológico y de los elementos rituales", $M M, 42$ (e.p.).

BENDALA, M., 1987: "Los cartagineses en España", Historia General de España y América, I-2, Madrid, 115-169.

BENDALA, M., 1989: "La génesis de la estructura urbana en la España antigua”, CuPAUAM, 16, 127-147.

BENDALA, M., 1990: "El plan urbanístico de Augusto en Hispania: precedentes y pautas macroterritoriales”, en Trillmich y Zanker (ed.), 1990, 25-42.

BENDALA, M. (ed.), 1993: La ciudad hispanorromana, Barcelona.

BENDALA, M., 1994: "El influjo cartaginés en el interior de Andalucía", Cartago, Gadir, Ebusus y la influencia púnica en los territorios bispanos, VIII Jornadas de Arqueología FenicioPúnica (Ibiza, 1993), Ibiza, 59-74.

BENDALA, M., 1998: "La ciudad entre los iberos, espacio de poder", en C. Aranegui (ed.), Barcelona, 1998, 25-34.

BENDALA, M., FERNÁNDEZ OCHOA, C., FUENTES, A. y ABAD, L., 1988: "Aproximación al urbanismo perromano y a los fenómenos de transición y potenciación tras la conquista", Los asentamientos ibéricos ante la romanización, Madrid (1986), 121-140.

BENDALA, M., CASTELO, R. y ARRIBAS, R., 1998: "La villa romana de El Saucedo (Talavera la Nueva, Toledo)", MM, 39, 298-310. 
BLASCO BOSQUED, Mª.C., 1993: El Bronce Final, Madrid.

BURILLO, F., 1998: Los celtiberos. Etnias y estados, Barcelona.

CARO BAROJA, J., 1974: Ritos y mitos equívocos, Madrid.

CERDEÑO, Ma.L., GARCÍA HUERTA, R., BAQUEDANO, I. y CABANEZ, E., 1996: "Contactos interior-zonas costeras durante la Edad del Hierro: los focos del noreste y suroeste meseteños", en Querol y Chapa, (ed.), 1996, I, 287-312.

CHIC GARCÍA, G., 1980: "Consideraciones sobre las inscursiones lusitanas en Andalucía”, Gades, 5, 15-25.

DOMÍNGUEZ MONEDERO, A., 1986: "La camapana de Aníbal contra los vacceos: sus objetivos y su relación con el inicio de la Segunda Guerra Púnica", Latomus, 45, 241 ss.

ESTEBAN BORRAJO, G., 1998: Cerámicas a torno pintadas orientalizantes, ibéricas e iberorromanas de Sisapo, Madrid.

FERNÁNDEZ GÓMEZ, F., 1986: Excavaciones arqueológicas en El Raso de Candeleda, Ávila.

FERNÁNDEZ-MIRANDA, M., 1986: “La estela de Las Herencias (Toledo)", Estudios en bomenaje al doctor Antonio Beltrán Martínez, Zaragoza, 463-476.

FERNÁNDEZ-MIRANDA, M. y PEREIRA SIESO, J., 1992: "Indigenismo y orientalización en la tierra de Talavera", AA.VV. 1992, 57-94.

FERNÁNDEZ OCHOA, C., ZARZALEJOS, M., HEVIA, P. y ESTEBAN, G., 1994: Sisapo I. Excavaciones arqueológicas en "La Bienvenida", Almodóvar del Campo (Ciudad Real), Toledo.

FUENTES DOMÍNGUEZ, A., 1993: “Las ciudades romanas de la Meseta Sur”, en M. Bendala (ed.), 1993, 160-189.

GALÁN DOMINGO, E., 1993: Estelas, paisaje y territorio en el Bronce Final del Suroeste de la Península Ibérica, Complutum extra 3, Madrid.

GALSTERER, H., 1971: Untersuchungen zum römischen Städtewesen auf der Iberischen Halbinsel, Berlín.

GARCÍA-BELLIDO, Mª.P., 1991-1992: "Sobre las dos supuestas ciudades de la Bética llamadas Arsa. Testimonios púnicos en la Baeturia Túrdula", Anas, 4-5, 81-92.

GARCÍA-BELLIDO, M².P., 1993: "Las cecas libiofenicias", Numismática bispano-púnica. Estado actual de la investigación. VII Jornadas de Arqueología Fenicio-Púnica (Ibiza, 1992), Ibiza, 97-146.

GARCÍA MARTÍN, P. (ed.), 1990: La Mesta, Madrid.

GARCÍA MORENO, L.A., 1989: "La Hispania anterior a nuestra Era: verdad, ficción y prejuicio en la historiografía antigua y moderna”, Actas del VII Congreso Español de Estudios Clásicos (Madrid, 1987), Madrid, 17-43.

GARCÍA MORENO, L.A., 1990: "Los orígenes de la Carpetania visigoda”, en Alvar, J. y Blánquez, C. (ed.), 1990, 229-249.

GONZÁLEZ, J. (ed.), 1999: Ciudades privilegiadas en el Occidente romano, Sevilla.

GONZÁLEZ-CONDE PUENTE, P., 1986: "Elementos para una delimitación entre vettones y carpetanos en la provincia de Toledo", Lucentum, V, 87-93.

GORGES, J.-G. (ed.), 1990: Les villes de Lusitanie romaine. Hiérarchies et territoires (Talence, 1988), Paris. 
GORGES, J.-G., 1990: "Villes et villas de Lusitanie”, en J.-G. Gorges (ed.), 1990, 91-113.

KLEIN, J., 1979: La Mesta, Madrid (1ª ed., 1920).

MANGAS MANJARRÉS, J. y CARROBLES SANTOS, J., 1992: "La ciudad de Talavera de la reina en época romana", AA.VV., 1992, 95-114.

MANGAS MANJARRÉS, J. y CARROBLES SANTOS, J., 1998: "Ciudades del área de la provincia de Toledo en época republicana", en J. Mangas, ed., Italia e Hispania en la crísis de la República romana. Actas del III Congreso Hispano-Italiano (Toledo, 1993), Madrid, 243-254.

MARTÍN BRAVO, A.M²., 1998: "Evidencias del comercio tartésico junto a puertos y vados de la cuenca del Tajo", AEspA, 71, 37-52.

MARTÍNEZ LILLO, S., 1998: Arquitectura militar andalusi en la Marca Media. El caso de Talabira. Talavera de la Reina.

MORALEDA OLIVARES, A. y PACHECO JIMÉNEZ, C., 1991: El puente romano de Talavera de la Reina, Talavera de la Reina.

MORENO ARRASTIO, F.J., 1990: "Notas al contexto de Arroyo Manzanas (Las Herencias, Toledo)", Actas del I Congreso de Arqueología de la Provincia de Toledo, Toledo, 277-308.

MORENO ARRASTIO, F.J., 1995: "La estela de Arroyo Manzanas (Las Herencias II, Toledo)", Gerión, 13, 275-294.

PACHECO, C., MORALEDA, A. y ALONSO, M., 1999: "Una nueva estela de guerrero en Toledo. La estela de Aldeanueva de San Bartolomé”, Revista de Arqueología, 213, 6-11.

PORTELA HERNANDO, D. y JIMÉNEZ RODRIGO, J.C., 1996: "Una nueva estela de guerrero. La estatua-menhir-estela de guerrero de Talavera de la Reina”, Revista de Arqueología, 188, 3643.

QUEROL, Ma.A. y CHAPA, T. (ed.): Homenaje al Profesor Manuel Fernández-Miranda, Complutum extra 6, Madrid.

ROLDÁN HERVÁS, J.M., 1975: Itineraria Hispana. Fuentes antiguas para el estudio de las vias romanas en la Península Ibérica, Valladolid-Granada.

RUIZ GÁLVEZ, M².L. y GALÁN, E., 1991: "Las estelas del Suroeste como hitos de vías ganaderas y rutas comerciales", Trab. Preh., 48, 257-273.

SALINAS DE FRIAAS, M., 1990: "Las ciudades romanas de Lusitania oriental”, en J.-G. Gorges (ed.), 1990, 255-263.

SANCHEZ MORENO, E., 2000: Vettones: bistoria y arqueología de un pueblo prerromano, Madrid.

SUÁREZ ÁlVAREZ, Mª.J., 1982: La Villa de Talavera y su tierra en la Edad Media (1369-1504), Oviedo-Toledo.

TOVAR, A., 1976: Iberische Landeskunde II: Lusitania, Baden-Baden.

TRILLMICH, W. y ZANKER, P. (ed.), 1990: Stadtbild und Ideologie. Die Monumentalisierung hispanischer Städte zwischen Republik und Kaiserzeit (Madrid, 1987), München.

VALIENTE CÁNOVAS, S., 1994: Excavaciones arqueológicas en "El Cerrón", Illescas (Toledo), Toledo.

VILLAR, F., 1995: Estudios de celtibérico y de toponimia prerromana, Salamanca. 